\title{
ANALYSIS OF EMISSION CHARACTERISTIC OF NM-DIESEL BLEND ON VCR DIESEL ENGINE
}

\author{
Chandan Kumar ${ }^{1}$, Ashish Nayyar ${ }^{2}$, Manish Bafna ${ }^{3}$, Ankit Agarwal $^{4}$, Ved Parkash ${ }^{5}$, \\ 1,2,4,5 Mechanical Engineering Department, Swami Keshvanand Institute of Technology, \\ G \& M, Jaipur \\ ${ }^{3}$ Mechanical Engineering Department, Jodhpur Institute of Engineering \& Technology, \\ Jodhpur
}

\begin{abstract}
The consumption of fuel is increasing resulting in pollution of environment with smoke and NOx due to the development in automobile and power sector. These emission contents smoke and NOx can be reduced by adding additives with diesel fuel. As these additives are very costly and hence becomes unviable. These additives decrease the performance of combustion.

Oxygenated compounds are most widely used among additives. The reason for this is the participation of their oxygen in reactions leading to better combustion and hence lowering the emission contents the molecular structure of the oxygen contents of additives directly influence on smoke reduction and the oxygen concentration of the fuel flame also effects the emission specially Nitro paraffin compound additives have high oxygen contents is then molecular structure. So we considered as oxygenated additives.
\end{abstract}

We have used nitro methane (NM) (2\%) as an additives with diesel while analyzing the emission characteristic on VCR Engine.

\section{KEY WORDS}

Emission characteristics, VCR engine, NM-Diesel blend, smoke meter, gas analyzer.

\section{INTRODUCTION}

In this paper we are going to analyze the emission characteristic of a VCR C.I. engine using NMdiesel blend of fuel. With increase in demand for diesel fuel and more concern for environmental emission has led to considerable research for better fuel formation in order to reduce the emission contents. The development of engine design has also help in reducing emission level considerably. The other way to reduce emission is by blending the diesel with different additives has to proved very successful and hence become a point of research in this field from last two decades.

\subsection{Health Effects of Diesel Engine Emission}

Diesel engine emission can effect health an can cause cancer and other pulmonary and cardiovascular diseases. Diesel engine emission is also a major contributor to particulate matter in DOI : 10.14810/ijmech.2015.4110 
the environment. The fine particles below $10 \mu \mathrm{m}$ effect respiratory morbidity and mortality. They also effect chest. It has been established that the exposure to diesel fumes in sufficient concentrations may lead to eye and nasal irritation but we have no evidence of any permanent effect. These emission inhalation leads to the development of cough and sputum and in case of higher exposure may lead to acute symptoms, primarily affecting the conjunctivae and upper respiratory tract i.e. nearly always reversible with in few days. These emission affects body respiratory system and the cardiovascular system and at the same time effects human health due to poor air quality.

\subsection{Additives}

We have so many additives available blended with diesel and used in CI engine. Those additives with oxygenated compounds are most widely used in Diesel, as the participation of their oxygen in reactions leads to a better combustion thus lowering emission. Their molecular structure and oxygen content have direct influence on soot reduction. In order to decrease soot formation, 11$21 \%$ volume of oxygenate chemicals should be blended with diesel fuel.

When additives are added they alter the physical and chemical properties such as density, viscosity, volatility and cetane index significantly. Nitro paraffin is one additive which have high oxygen content in then molecular structure.

By addition of additives, we can improve the performance via the increase of thermal energy output and combustion product alteration.

\subsection{The Merits of Additives}

Following are the merits of additives:-

- $\quad$ Engine Performance:- It has been found out that some of additives improves thermal efficiency upto $19 \%$ without affecting the torque.

- $\quad$ Emissions Reduction:- Diesel additives can decreases pollutants and greenhouse gas emissions upto $55 \%$ or more.

\subsection{The Demerits of Additives}

Following are the demerits of additives:-

- $\quad$ Fuel Cost:- The high cost of additives increases the cost of fuel.

- $\quad$ Preparation of blend:- Preparation of diesel additives blend are difficult in some cases.

\subsection{Nitromethane}

Nitromethane is an organic compound with the chemical formula $\mathrm{CH}_{3} \mathrm{NO}_{2}$. It is the simplest organic nitro compound. It is generally used as a solvent in many industrial applications e.g. in extractions as a reaction medium and as a cleaning solvent. It is a less viscous and high polar liquid. Its application as an intermediate in-organic synthesis, in the manufacturing of pharmaceutical, pesticides, explosive and fiber coating has been found useful. 


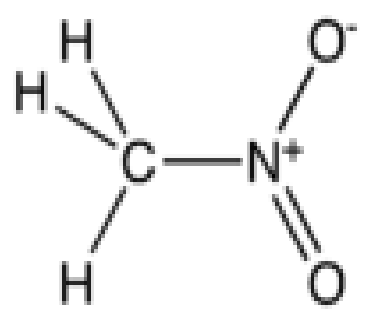

Fig. 1: Structure of Nitromethane

\subsection{Properties of Diesel and Additives:}

Following properties are essential to check before using the additives in internal combustion engines. Table 1 gives the comparison of physical and combustion properties of diesel and Nitromethane.

Table 1: Comparison of Physical and Combustion Properties of diesel and NM [18] [21].

\begin{tabular}{|l|c|c|}
\hline & Diesel & Nitromethane \\
\hline Molecular Formula & $\mathrm{C}_{10} \mathrm{H}_{20}-\mathrm{C}_{15} \mathrm{H}_{28}$ & $\mathrm{CH}_{3} \mathrm{NO}_{2}$ \\
\hline Molecular Weight & 170 & 61.04 \\
\hline Hydrogen Content (wt\%) & $12-15$ & 4.8 \\
\hline Carbon Content $(\mathrm{wt} \%)$ & $86-88$ & 19.5 \\
\hline Oxygen Content $(\mathrm{wt} \%)$ & 0 & 52.4 \\
\hline Density $\left(\mathrm{Kg} / \mathrm{m}^{3}\right)\left(20^{\circ} \mathrm{C}\right)$ & 837 & 1138 \\
\hline Specific Gravity & .836 & 1.137 \\
\hline Latent heat of vaporization $(\mathrm{KJ} / \mathrm{Kg})$ & 255 & 564 \\
\hline Cetane Number & 50 & $\mathrm{NA}$ \\
\hline Viscosity $\left(40^{\circ} \mathrm{C}\right) \mathrm{cSt}$ & 4.8 & 4.8 \\
\hline Lower heating value $(\mathrm{MJ} / \mathrm{Kg})$ & 42 & 11.2 \\
\hline Flash Point $\left({ }^{\circ} \mathrm{C}\right)$ & $62-84$ & 34 \\
\hline Boiling Point $\left({ }^{\circ} \mathrm{C}\right)$ & $181-362$ & $101-102$ \\
\hline
\end{tabular}

Nitromethane used as an additive with diesel fuel for C.I. engine as it has :-

- $\quad$ Auto ignition temperature high.

- $\quad$ High Oxygen Contents.

- Very little Hydrogen and carbon contents.

\section{Test Engine Selection and Development of Experimental Setup}

The parameters of the test Engine for research work are as below

- $\quad$ Single Cylinder with bore $80 \mathrm{~mm}$ and Stroke $110 \mathrm{~mm}$.

- $\quad$ Four stroke direct injection.

- $\quad$ Naturally aspirated VCR multi fuel engine.

- $\quad$ Power output 5 HP. 
- $\quad$ Manufacture by TTE Banglore.

The engine is loading by eddy current dynamometer. The VCR engine is start by hand cranking/self start.

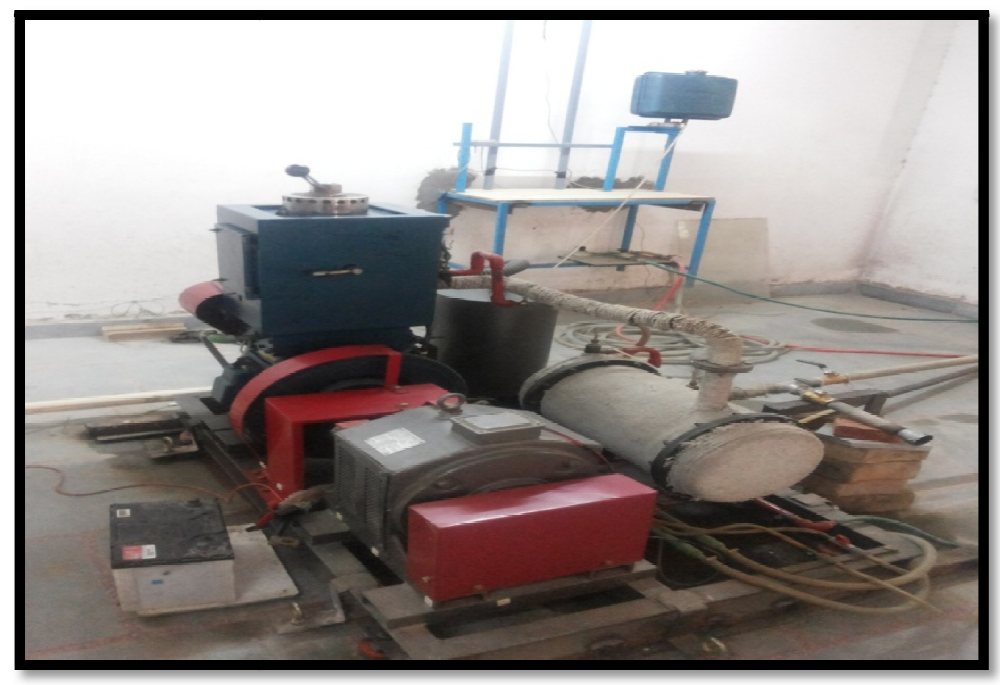

Fig.2: Experimental Set up of VCR engine

\section{Exhaust Emission Measurement}

The exhaust gas compositions have been measured using i3sys gas exhaust analyzer (EPM1601) and AVL smoke meter (437C):

\subsection{I3sys Gas Exhaust Analyzer}

Gas analyzer is used to measure concentrations of Carbon Monoxide, Hydrocarbons and Carbon Dioxide based on Non-Dispersive Infra Red principle and Oxygen, Oxides of Nitrogen and Sulphur are measured by Electro Chemical principle. The principal of the gas analyzer is based on the amount of infrared energy absorbed by a compound in a cell is proportional to the concentration of the compound. The analyzer is equipped with advanced microprocessor technology with printer and RS 232 serial port for a personal computer interface. 
International Journal of Recent advances in Mechanical Engineering (IJMECH) Vol.4, No.1, February 2015

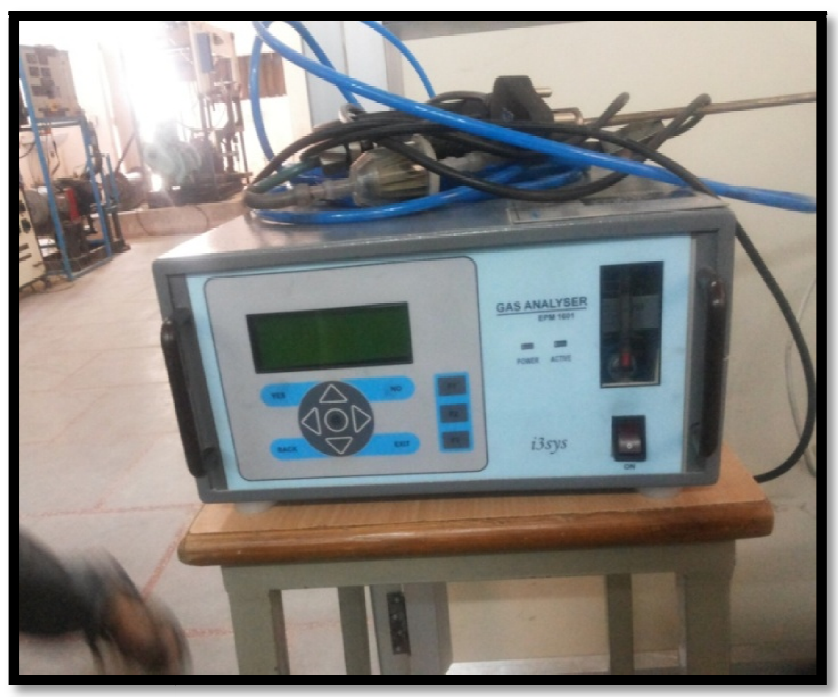

Fig. 3: View of I3sys Gas Exhaust Analyzer

\subsection{AVL Smoke Meter}

Smoke meter is used to measure smoke density and smoke opacity based on the light absorption coefficient principle. The smoke meter is equipped with advanced microprocessor technology with printer and RS 232 serial port for a personal computer interface.

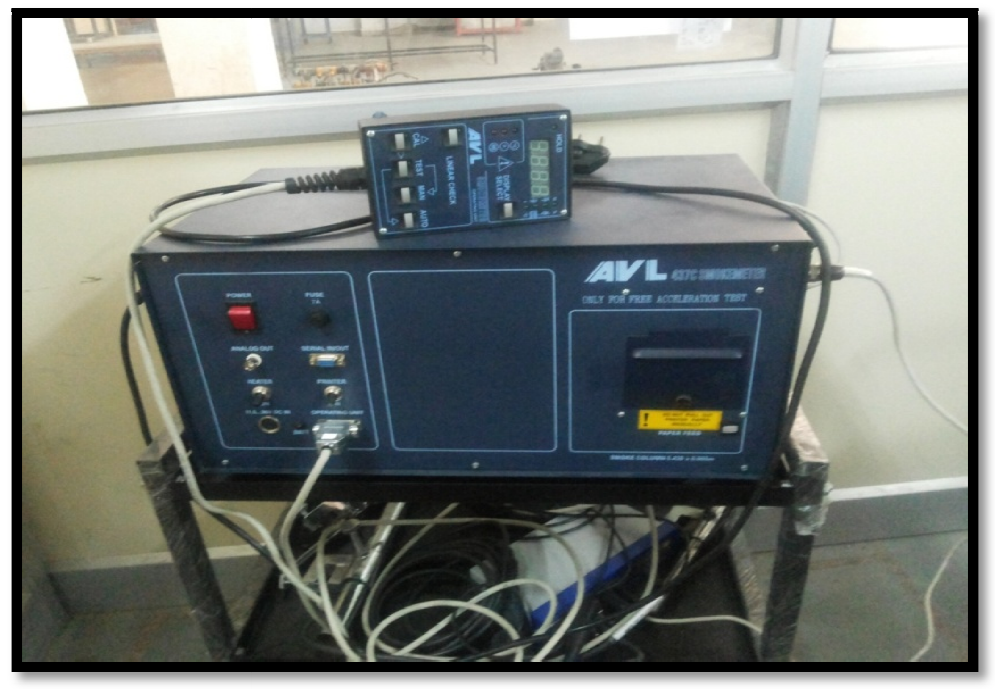

Fig. 4: View of AVL Smoke meter 


\section{EMISSION PARAMETERS}

The main emissions are carbon monoxide $(\mathrm{CO})$, hydrocarbons $(\mathrm{HC})$, oxides of nitrogen $\left(\mathrm{NO}_{\mathrm{x}}\right)$ and smoke opacity during combustion process from C.I. engine. The results were compared between diesel at compression ratio 17.5 and Nitromethane- diesel blend at compression ratio 17.5 and 16.5 .

\subsection{Carbon Monoxide}

The graph shown in fig.5 is drawn between brake power $(\mathrm{kW})$ and carbon monoxide emission (ppm). The Carbon for Nitromethane-diesel blends higher than pure diesel operation for both compression ratios. The result revels that we decrease the compression ratio from 17.5 to 16.5 . $\mathrm{CO}$ emission increases, it may because of less intermolecular reactivity at low compression ratio.

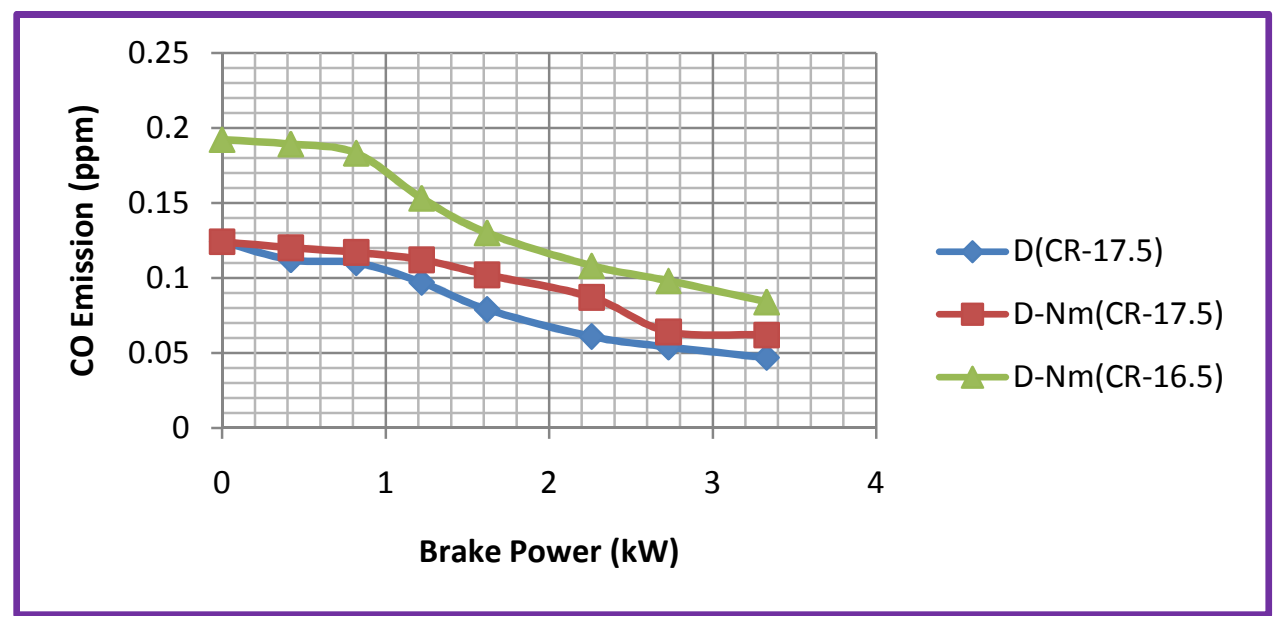

Fig.5: Change in $\mathrm{CO}$ emission with BP

\subsection{Unburnt Hydrocarbons}

The graph shown in fig.6 is drawn between brake power $(\mathrm{kW})$ and hydrocarbons (ppm). The HC emission of diesel at compression ratio 17.5 is less as compare to Nitromethane-diesel blend at compression ratio 16.5 and slightly less as compare to Nitromethane-diesel blend at compression ratio 17.5. 


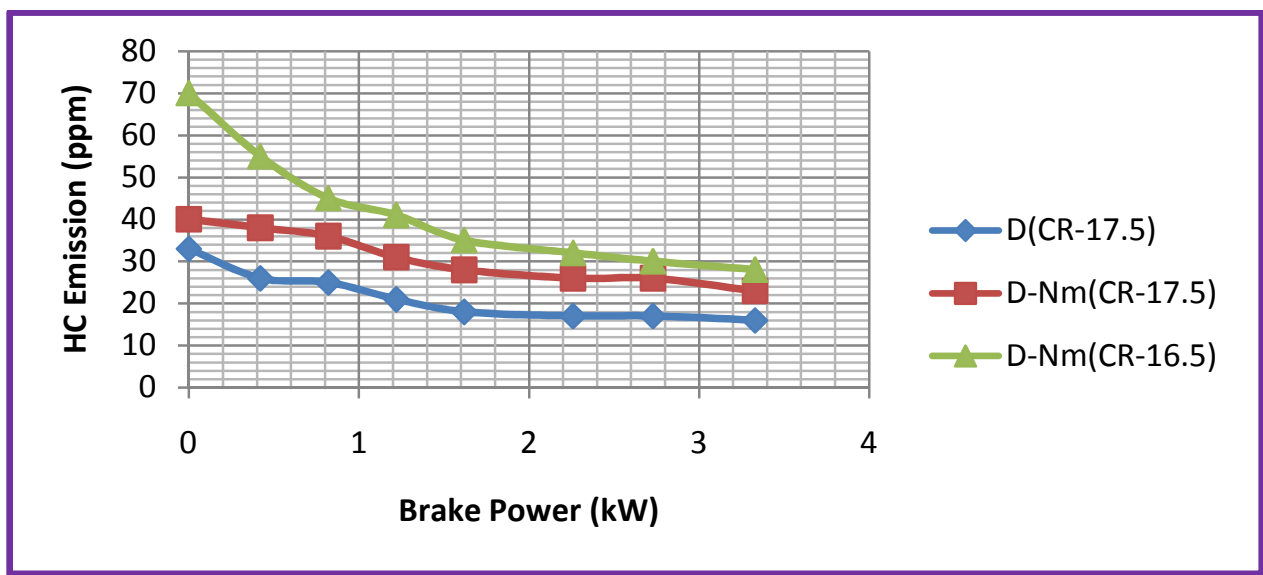

Fig. 6: Change in $\mathrm{HC}$ emission with $\mathrm{BP}$

\subsection{Oxides of Nitrogen $\left(\mathrm{NO}_{\mathrm{x}}\right)$}

The graph shown in fig.7 is drawn between brake power $(\mathrm{kW})$ and oxides of nitrogen $(\mathrm{ppm})$. The NOx emission of diesel at compression ratio 17.5 is slightly high as compare to Nitromethanediesel blend at compression ratio 17.5 and is high enough as compare to Nitromethane-diesel blend at compression ratio 16.5 .

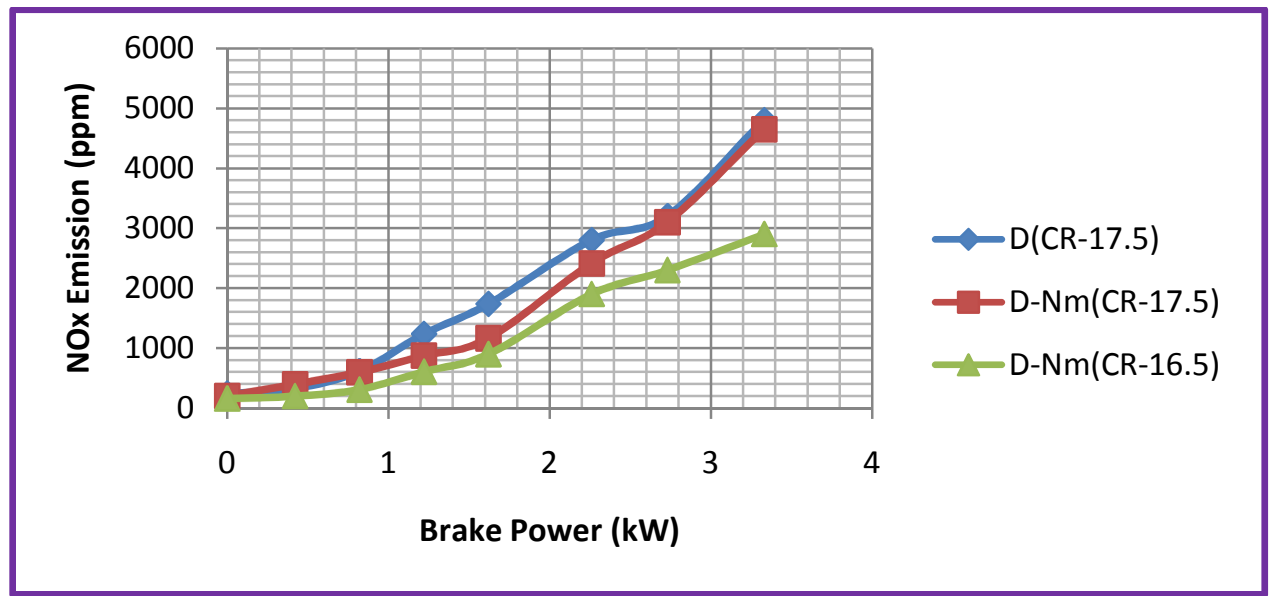

Fig. 7 Change in NOx emission with BP

\subsection{Opacity (N)}

The opacity graph shown in fig. 8 is drawn between brake power (kW) and opacity (\%). The opacity emission of NM-diesel blend at compression ratio 16.5 is enough high as compare to diesel at compression ratio 17.5 and enouh high as relative to NM-diesel blend at compression ratio 17.5 . 


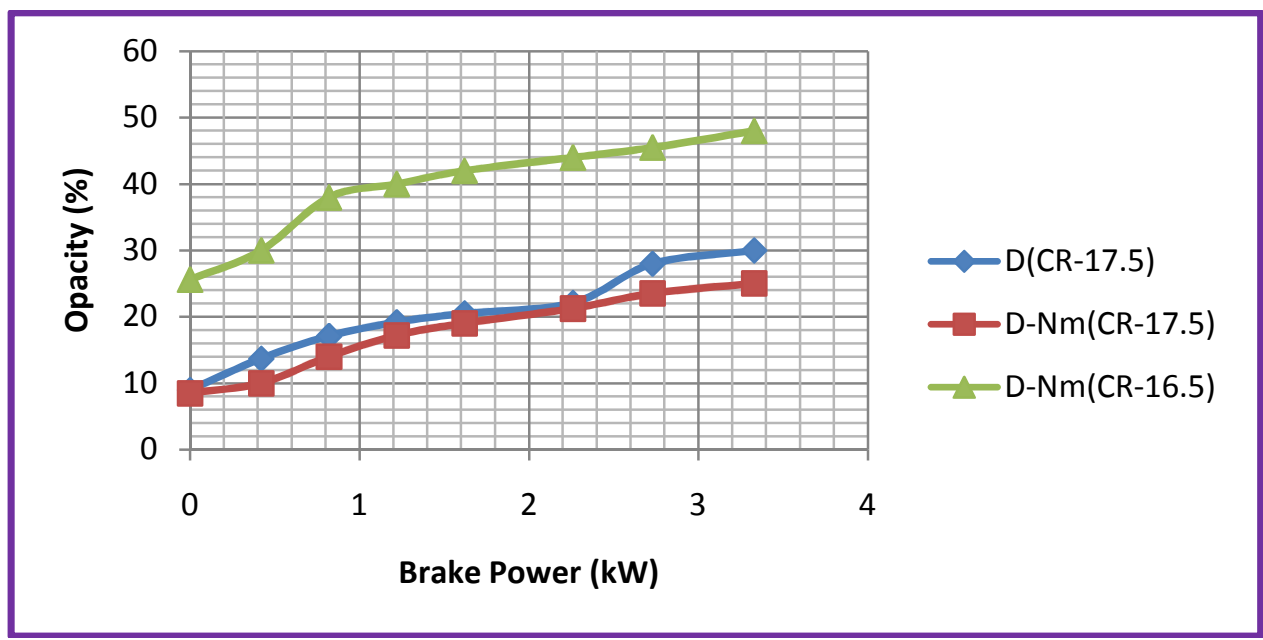

Fig. 8: Change in Opacity emission with BP

\subsection{Smoke density $(K)$}

The graph shown in fig.9 is drawn between brake power $(\mathrm{kW})$ and smoke density $\left(\mathrm{m}^{-1}\right)$. The smoke density emission of NM-diesel blend at compression ratio 16.5 is high as compare to diesel fuel at compression ratio 17.5 and high as relative to NM-diesel blend at compression ratio 16.5 .

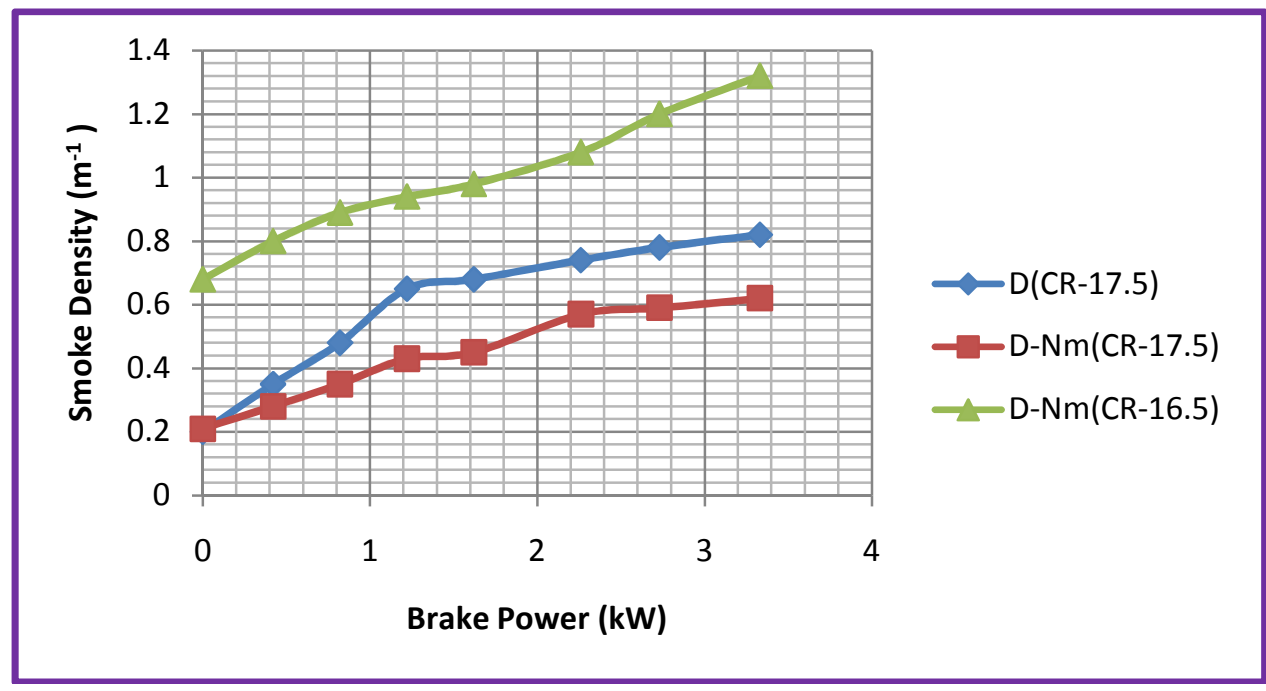

Fig. 9: Change in Smoke density emission with BP

The increased smoke at lower compression ratio is because of less efficient combustion at low pressure and temperature. 


\section{CONCLUSIONS}

The following conclusion has been drawn from the experiments and analysis of C.I. Engine combustion with pure diesel at compression ratio 17.5 and NM-Diesel blend at compression ratio 17.5 and 16.5 .

- The CO emission of NM-Diesel blend at compression ratio 17.5 is more as compare to diesel, at same compression ratio. As we reduce compression ratio up to 16.5 emission of $\mathrm{CO}$ will be increased. The increases of $\mathrm{CO}$ are prolonged at low loads.

- $\quad$ The $\mathrm{HC}$ emission shows the same trends as CO.

- $\quad$ NOx emission of NM-Diesel blend at compression ratio 17.5 is lower as compare to diesel at same compression ratio. As compression ratio reduced to 16.5 the NOx emission reduced at a great extend for all loads.

- $\quad$ The smoke of NM-Diesel blend at compression ratio 17.5 is less as compare to diesel at same compression ratio. At lower compression ratio the smoke level has been increased.

Only NOx has been reduced by lowering the compression ratio, otherwise $\mathrm{CO}, \mathrm{HC}$ and smoke has been increased due to reduced compression ratio. Thus it is concluded that lowering the compression ratio from normal (i.e. 17.5) to 16.5 is not in favour for emission of C.I. Engine with NM-Diesel blend.

\section{REFERENCES}

[1] Economic Survey 2010-11, Economic Division, Ministry of Finance, Government of India, 2011.

[2] Statistical Abstracts India 2010-11, Central Statistical Organization, Ministry of Statistics and Programme Implementation, Government of India, 2011.

[3] Singh Gyanendra: "An Analytical Approach to Farm Mechanization in India-Agricultural Machinery Development and Promotion", Journal of Rural Development, Volume, 7(2), 1999, Pages 297-319.

[4] “Agricultural Equipment Sector in India: A Report", India Brand Equity Foundation, India 2009-10.

[5] Agricultural Statistics at a Glance, Directorate of Economics and Statistics, Department of Agriculture and Cooperation, Ministry of Agriculture, Government of India, 2002-2010.

[6] “Agriculture Equipment market in India: An Overview”, Zinnov L.L.C., 2006.

[7] "World Development Report 2008: Agriculture for Development", The World Bank, Washington D.C., U.S.A., 2008-09.BP Statistical Review of World Energy, U.K., 2010-2011.

[8] Indian Petroleum and Natural Gas Statistics 2009-10, Economics and Statistics Division, New Delhi, Ministry of Petroleum and Natural Gas, Government of India, 2010.

[9] Annual Report 2010, Ministry of Petroleum and Natural Gas, Government of India, 2010

[10] "Impact of High Oil Prices on Indian Economy", Report for Federation of Indian Chambers of Commerce and Industry (FICCI), 2005, Pages 1-40.

[11] Metin Guru, Ugur Karakaya, Duran Altiparmak and Ahmet Alicilar, "Improvement of Diesel fuel properties by using additives”, Energy Conversion and Management 43, pp. 1021-1025, 2002.

[12] Ali Keskin, Metin Guru and Duran Altiparmak, "Influence of metallic based fuel additives on performance and exhaust emissions of diesel engine", Energy Conversion and Management 52, pp. 60-65, 2011. 
[13] Eliana Weber de Menezes, Rosangela da Silva, Renato Cataluna and Ricardo J.C. Ortega, "Effect of ethers and ether/ethanol additives on the physicochemical properties of diesel fuel and on engine tests", Fuel 85, pp. 815-822, 2006.

[14] AlirezaValipour, "A Review on Effect of Fuel Additives on Combustion, Performance and Emission Characteristics of Diesel and Biodiesel Fuelled Engine”, IJAIEM, Volume 3, Issue 1, January 2014.

[15] W.M. Yang , H. An, S.K. Chou, K.J. Chua, B. Mohan, V. Sivasankaralingam, V. Raman, A. Maghbouli and $\mathrm{J}$. Li, "Impact of emulsion fuel with nano-organic additives on the performance of diesel engine", Applied Energy, 2013.

[16] Murat Karabektas and Murat Hosoz, "Performance and emission characteristics of a diesel engine using isobutanol-diesel fuel blends", Renewable Energy 34, pp. 1554-1559, 2009.

[17] P.Sreenivasulu, B. Durga Prasad, G. Naga Malleswar Rao and S.Sudhakar Babu, "Importance and role of additives for estimating performance and emission in C.I Engine using alcohols as fuels- A Study", IJIRSET, Vol. 2, Issue 8, August 2013.

[18] Gong Yanfeng, Liu Shenghua, Guo Hejun, Hu Tiegang and Zhou Longbao, "A new diesel oxygenate additive and its effects on engine combustion and emissions", Applied Thermal Engineering 27, pp. 202-207, 2007.

[19] Mojtaba Saei Moghaddam, Mohammad Mataei Moghaddam, Sina Aghili, Ali Absalan and Ali Najafi, "Performance and Exhaust Emission Characteristics of a CI Engine Fueled with Diesel-Nitrogenated Additives", International Journal of Chemical Engineering and Applications, Vol. 3, No. 5, October 2012.

[20] K.Manikanta, K.Anil and B.Manoj Prabhakar, "Performance Analysis of Variable Compression Ratio Engine using Diesel", AMAE Int. J. on Production and Industrial Engineering, Vol. 01, No. 01, Dec 2010.

[21] Mojtaba Saei Moghaddam and Abdolsamad Zarringhalam Moghaddam, "Performance and exhaust emission characteristics of a CI engine fueled with diesel-nitrogenated additives", chemical engineering research and design, 2014.

[22] Kanako Sekimotoa, Satoshi Inomataa, Hiroshi Tanimotoa, Akihiro Fushimia, Yuji Fujitania, Kei Satoa and Hiroyuki Yamadab, "Characterization of nitromethane emission from automotive exhaust", Atmospheric Environment, Volume 81, pp.523-531, December 2013.

[23] Deepali Bharti, Professor Alka Agrawal, Assistant Professor Nitin Shrivastava, Bhupendra Koshti, "Experimental Investigation and Performance Parameter on the Effect of N-Butanol Diesel Blends on an Single Cylinder Four Stroke Diesel Engine" , International Journal of Scientific and Research Publications, Volume 2, No. 8, August 2012. 